\title{
Effects of norfloxacin on fetal development in pregnant female
}

\section{rats}

\author{
Eman Soliman ${ }^{1}$, Nani Nasreldin², Rasha Abdel-Gelil ${ }^{1}$, Galal Youssef ${ }^{3}$, Magdy Amer ${ }^{1}$ \\ ${ }^{1}$ Department of Pharmacology, Faculty of Veterinary Medicine, Mansoura University, 35516 Mansoura, Egypt \\ 2 Department of Pathology and Clinical Pathology, Faculty of Veterinary Medicine, New Valley University \\ ${ }^{3}$ Department of Anatomy Faculty of Veterinary Medicine, Mansoura University, 35516 Mansoura, Egypt
}

\section{ARTICLE HISTORY}

Received: 02.05.2020

Revised: 12.07 .2020

Accepted: 13.07 .2020

Address correspondences to Eman Soliman; Tel: 01093552674; Fax: 0020502379952; E-mail:

solimaneman813@gmail.com

\section{ABSTRACT}

\begin{abstract}
Objective: To evaluate the effect of norfloxacin on pregnant female rats.
Animals: 30 pregnant female rats (170-200 gm of weight and 3.5-4 months age).

Design: Randomized controlled study.

Procedures: The effect of orally administrated norfloxacin, given twice daily for 10 successive days, on the fetal development in pregnant female rats at therapeutic $(35 \mathrm{mg} / \mathrm{kg})$ and double therapeutic $(70 \mathrm{mg} / \mathrm{kg})$ doses was investigated in pregnant female rats. At $6^{\text {th }}-15^{\text {th }}$ day of pregnancy, 30 females were classified, in groups of ten rats, into 3 groups. Group 1 (control group): rats were given distilled water orally. Group 2: rats were given norfloxacin at a dose rate of $35 \mathrm{mg} / \mathrm{kg}$ bwt. Group 3: rats were given norfloxacin at a double therapeutic dose of $70 \mathrm{mg} / \mathrm{kg}$ bwt. At $20^{\text {th }}$ day of gestation all pregnant rats were anesthetized to determine the changes; if any; in fetal development (morphological, visceral, skeletal and histopathological examinations) and on treated dams (biochemical parameters of serum and histopathological alterations in placenta, liver and kidney).

Results: Administration of norfloxacin, in both doses, to pregnant females decreased the number of viable feti, fetal body weight and crown-rump length, and increased the number of resorbed feti $(P<$ 0.05). It also induced visceral and skeletal abnormalities in feti. Histopathological examination of internal organs to both dams and feti revealed pathological alterations in liver and kidney of both, and placenta of the dam. Administration of norfloxacin at both therapeutic and double therapeutic doses increased maternal serum transferases levels (ALT and AST), decreased serum albumin and total portein levels, and increased serum levels of urea and creatinine $(P<0.05)$.

Conclusion and clinical relevance: High doses of norfloxacin induce fetal defects and abnormalities in early stage of gestation in rats.
\end{abstract}

Keywords: Norfloxacin, pregnancy, rats, anomalies, fetus, histopathology.

\section{INTRODUCTION}

Numerous therapeutic agents that are used in the Veterinary field for the control of diseases in pregnant females may produce teratogenic effects. The development of fetus during pregnancy includes the formation of blastocyte, organogenesis, histogenesis and fetal maturation. Several studies indicated that during blastocytes formation some teratogenic agent can interfere with the cell division of the embryo. The malformations that result from the use of teratogenic drugs depend on at which stage of pregnancy the exposure occur. During organogenesis, the alterations occur in the brain, eye, heart, blood vessels, skeleton, limbs and urogenital system [1].

Particular drugs can pass the placental barrier and enter the fetal circulation, induce therefore structural abnormalities in the neonate at birth extending to undefined period [2].

During past decades, it has become increasingly evident that human and animal embryos are subjected to the toxic effects of many drugs, such as antibacterial agents used in treatment of serious diseases occurring during pregnancy including, among others, fluoroquinolones [3].
Fluoroquinolone antibiotics are commonly used to treat a variety of infections, including urinary tract, respiratory tract, gastrointestinal tract, skin, bone, and joint infections. The popularity of fluoroquinolone antibiotics has increased because of their broad antimicrobial spectrum, multiple approved indications, and favorable pharmacokinetics [4].

Norfloxacin is a synthetic antimicrobial agent of the second-generation fluoroquinolones. Like other fluoroquinolones, it acts by inhibition of DNA gyrase; the enzyme required for the proper supercoiling of bacterial chromosomes. It has a wide spectrum of activity, acting against many $G$-ve and $G$ +ve bacteria, and is rapidly bactericidal at low concentration. It can be used for the treatment of urinary tract infections that occur during the first trimester of pregnancy [5].

The current work was therefore designed to explain the adverse effects; if any; of norfloxacin on fetal development in pregnant female rats.

\section{MATERIALS AND METHODS \\ 2.1. Drug}


Norfloxacin was purchased from ATCO Pharma for Pharmaceutical Industries, Egypt, and used in form of oral solution (300 mg of norfloxacin acid base/1 mL). Norfloxacin was administered orally at a therapeutic dose of $35 \mathrm{mg} / \mathrm{kg}$ bwt twice daily for 10 days. The dose of norfloxacin was determined according to Paget and Barnes [6].

\subsection{Animals}

Thirty mature healthy female albino rats were obtained from The Laboratory Animal Colony, Helwan University, Egypt, and were used in the study. The animals were 3.5-4 months of age, and 170-200 gm of weight. Pelleted food and tap water were provided ad libitum.

\subsection{Determination of zero day of pregnancy}

Rats were examined periodically to ensure that they were always in a regular estrous cycle. Vaginal smears from the animals were examined daily, and the female that was determined in estrus was paired with a male in a separate cage. In the following morning a vaginal smear was taken from the female rat to verify the first day of gestation. Presence of sperms in the obtained vaginal smear was used as an indicator of the zero day of gestation [7]. Pregnancy was further confirmed by microscopic examination of vaginal smears, and the persistence of diestrus indicated pregnancy. Body weight was recorded regularly and prominent increases were observed chiefly after 10 days from the determined day of pregnancy [8].

Norfloxacin was given orally during the organogenesis period (from the $6^{\text {th }}$ to the $15^{\text {th }}$ day of pregnancy), the period during which organs are sensitive to the effect of toxic substances [9].

\section{Grouping and drug administration}

The pregnant rats were categorized into three equal groups of 10 rats each, and were given norfloxacin by stomach tube twice daily for 10 consecutive days (from the $6^{\text {th }}$ till the $15^{\text {th }}$ day of pregnancy) as follows:

(G1): animals received $0.5 \mathrm{ml}$ distilled water orally. (G2): animals received a therapeutic dose of norfloxacin at the rate of $35 \mathrm{mg} / \mathrm{kg}$ bwt. (G3): animals received a double therapeutic dose of norfloxacin at a dose of $70 \mathrm{mg} / \mathrm{kg}$ bwt.

Female rats were kept under a daily observation scheme until the $20^{\text {th }}$ day of gestation. Afterwards, they were weighed and euthanized by intraperitoneal injection of large doses of thiopental sodium (EIPICO, Egypt). Caesarian sections were performed to examine the effects of norfloxacin on fetal development via morphological, visceral, skeletal and histopathological examinations.

\section{Examination and sampling:}

\subsection{Morphological examination}

Morphological examination of feti was performed according to the method described by Hayes [10].

\subsection{Visceral examination:}

Feti were preserved in Bouin's fixative, and were rinsed with cold water and examined grossly according to Hayes [11].

\subsection{Skeletal examination}

Skeletal examination of feti were conducted according to Staples [12], and examination by hand lens was done according to the method described by Hayes [10].

\subsection{Histopathological examination}

Specimens from liver, kidney, placenta of dams, and liver, kidney of feti were collected on the $20^{\text {th }}$ day of pregnancy, and were preserved in $20 \%$ neutral buffered formalin [13]. The slides were examined under a photomicroscope with an Olympus DP25 digital camera.

\subsection{Blood sampling}

On the $20^{\text {th }}$ day of pregnancy, 5 rats from each group were anesthetized using ketamine hydrochloride and fresh blood samples were immediately collected from eye plexus using non-heparinized microhematocrit tubes in plain centrifuge tubes, and were kept in an inclined position for 20 minutes at room temperature. Blood samples were put in the refrigerator overnight to avoid glycolysis and complete clot retraction, and were then centrifuged at $3000 \mathrm{rpm}$ for 10 minutes and clear sera were separated carefully, collected and stored in Eppendorf tubes at -20 o $C$ until biochemical analysis [14].

\subsection{Serum biochemical analysis}

ALT, AST, TP, albumin, urea and creatinine were measured using commercial kits (Diamond diagnostic, Egypt). All serum biochemical parameters were assayed spectrophotometrically (Spectrophotometer SP50, Gallen KAMP, U.K) according to enclosed pamphlets.

\section{Statistical analysis}

Data were analyzed using computerized SPSS program version 16. Results are presented as means + SE. Data were analyzed by one-way ANOVA followed by Duncan's test. Means are considered significant at $\mathrm{P} \leq .05$.

\section{RESULTS}

\subsection{Morphological examination}

Oral administration of norfloxacin in both doses to female rats from $6^{\text {th }}$ to $15^{\text {th }}$ days of gestation caused decrease the number of viable feti, fetal body weight and crown-rump length, and increased the number of resorbed feti (Table 1 and Figure 1).

\subsection{Visceral examination}

The administration of norfloxacin in both doses to pregnant rats during organogenesis period induced diverticulum dilatation in the brain, hypoplasia of thymus gland, thickening of the ventricular wall of the heart (cardiac hyperplasia), a slight unilateral or bilateral widening of the renal pelvis and hypoplasia of one or both kidneys (Table 2 and Figure 1). 
Table 1. Effect of norfloxacin on body weight and length of feti obtained from pregnant female rats after oral administration of 35 and $70 \mathrm{mg}$ norfloxacin/kg bwt from the $6^{\text {th }}$ to $15^{\text {th }}$ day of pregnancy twice daily.

$\begin{array}{lll}\text { Group } & \text { Fetal body weight (gm) } & \text { Fetal body length }(\mathrm{cm}) \\ \text { G1 } & 4.60 \pm 0.05^{\mathrm{a}} & 4.53 \pm 0.06^{\mathrm{a}} \\ \text { G2 } & 3.64 \pm 0.16^{\mathrm{b}} & 3.18 \pm 0.04^{\mathrm{b}} \\ \text { G3 } & 2.75 \pm 0.07^{\mathrm{c}} & 2.45 \pm 0.10^{\mathrm{c}}\end{array}$

Within the same column mean carry different superscript differ significan $(P<0.05)$.
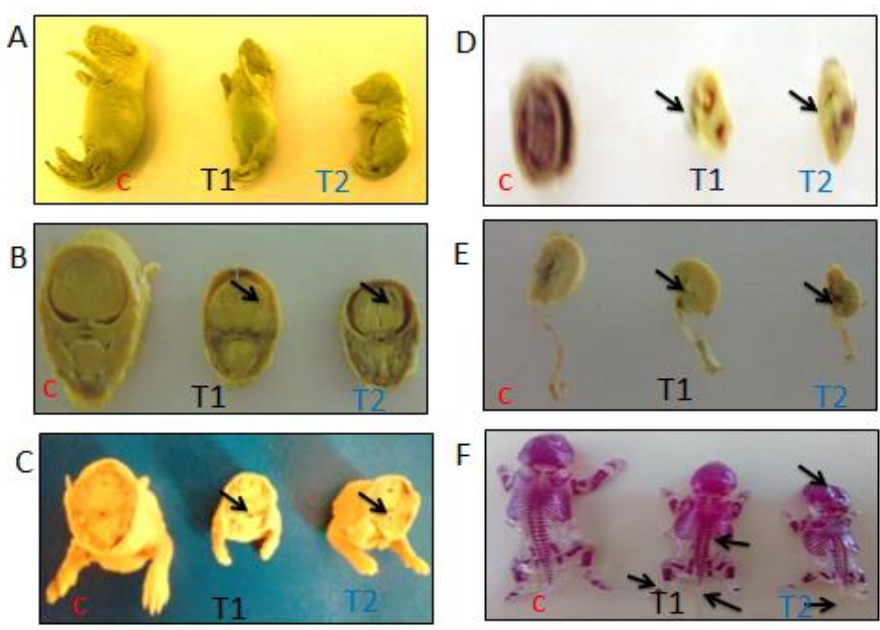

Figure 1. A: C: Lateral view of 3 rat feti arranged from left to right showing a decrease in fetal size. B: Cross section in brain of feti showing diverticulum dilation in the brain. C: Cross section in head of the feti showing thymus hypoplasia. D: Cross section in heart ventricles of the feti showing thickening of the ventricular wall of the heart. E: Cross section in kidney of the feti showing widening of the renal pelvis and kidney hypoplasia. F: A dorso-ventral view of skeleton of rat feti arranged from left to right showing absence of caudal vertebrae and irregular and short ribs in T1, incomplete ossification of skull and absence of digits of fore and hind limb in T2. (C) Control group (T1) dams treated orally with therapeutic dose of norfloxacin $35 \mathrm{mg} / \mathrm{kg}$ bwt from $6^{\text {th }}$ to $15^{\text {th }}$ day of pregnancy, and (T2) dams treated orally with double therapeutic dose of norfloxacin $70 \mathrm{mg} / \mathrm{kg}$ bwt from $6^{\text {th }}$ to $15^{\text {th }}$ day of pregnancy.

Table 2. Visceral abnormalities in feti obtained from pregnant female rats after oral administration of 35 and $70 \mathrm{mg}$ norfloxacin/kg bwt from the $6^{\text {th }}$ to $15^{\text {th }}$ day of pregnancy twice daily. $(n=10)$.

$\begin{array}{llll}\text { Parameters } & \text { G1 } & \text { G2 } & \text { G3 } \\ \text { Number of examined feti } & 20 & 20 & 20 \\ \text { Brain } & - & 10(50 \%) & 13(65 \%) \\ \text { Thymus } & - & 6(30 \%) & 8(40 \%) \\ \text { Heart } & - & 9(45 \%) & 12(60 \%) \\ \text { Kidney } & - & 7(35 \%) & 11(55 \%)\end{array}$

\subsection{Skeletal examination}

The administration of norfloxacin in both doses to pregnant rats during organogenesis period caused impairment of skull ossification, irregular ribs, absence of strenebrae, caudal vertebrate and digital bones of fore and hind limb with absence of some metacarpal and metatarsal bone. (Table 3 and Figures 1).
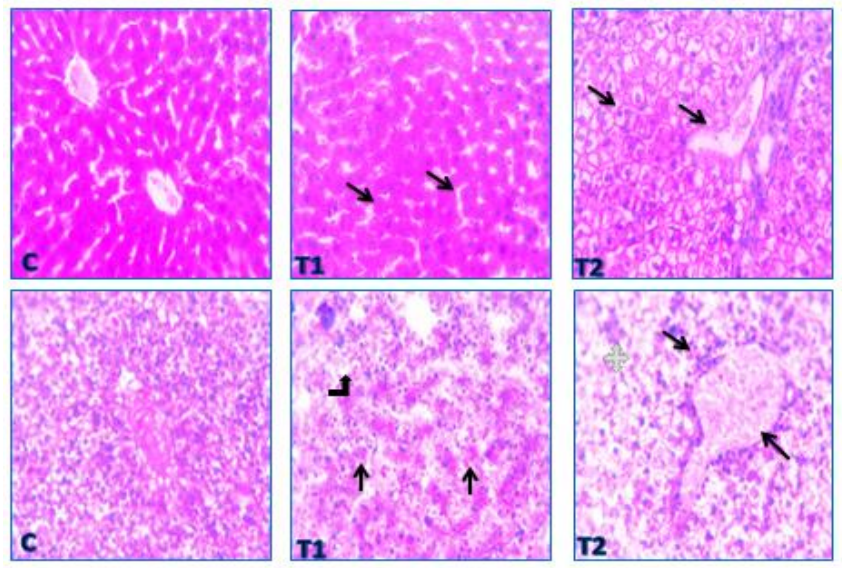

Figure 2. A: Liver section of female rat where (C) liver of control rat showing normal histological structure, (T1) liver section of rats given therapeutic dose of norfloxacin showing minor vacuoles in hepatocytes (arrows), (T2) liver section of rats given double therapeutic dose of norfloxacin showing diffuse hydropic degeneration (arrows). H\&E, X: 200. B: Liver section of feti where (C) liver section of feti obtained from control rats showing normal tissue architecture and cellular details, (T1) liver section of feti from rats given therapeutic dose of norfloxacin showing congested hepatic sinusoids (arrows) and prominent Kupffer cells (curved arrow), (T2) liver section of feti from rats given double therapeutic dose of norfloxacin showing congested portal vein surrounded with mononuclear cells $\left(\mathrm{MNC}_{\mathrm{s}}\right.$ ) infiltration (arrows), markedly degenerated hepatocytes (asterisk). H\&E, X: 200.

Table 3. Skeletal deformities in feti obtained from pregnant female rats after oral administration of 35 and $70 \mathrm{mg}$ norfloxacin/kg bwt from the $6^{\text {th }}$ to $15^{\text {th }}$ day of pregnancy twice daily $(n=10)$.

\begin{tabular}{|c|c|c|c|}
\hline Parameters & G1 & G2 & G3 \\
\hline Number of examined feti & 20 & 20 & 20 \\
\hline Impairment of skull ossification & - & $8(40 \%)$ & $11(55 \%)$ \\
\hline Absence or dislocation of strenebrae & - & $6(30 \%)$ & $9(45 \%)$ \\
\hline Absence of digital bone & - & $8(40 \%)$ & $10(50 \%)$ \\
\hline Absence of caudal vertebrate & - & $5(25 \%)$ & $7(35 \%)$ \\
\hline Absence of metatarsal bone & - & - & $1(5 \%)$ \\
\hline Absence of metacarpal bone & - & $1(5 \%)$ & $2(10 \%)$ \\
\hline
\end{tabular}

\subsection{Biochemical analysis}

Oral administration of norfloxacin in both therapeutic and double therapeutic doses increase serum levels of transferases (ALT and AST), urea and creatinine, and decreased serum levels of total portein and albumin (Table 4).

\subsection{Histopathological findings}

Histopathological examination of the effects of oral administration of norfloxacin in both doses to female rats from $6^{\text {th }}$ to $15^{\text {th }}$ days of gestation revealed various pathological alterations (Figure 2, 3, and 4) as follows.

\subsubsection{Liver}

The administration of therapeutic dose of norfloxacin (35 $\mathrm{mg} / \mathrm{kg}$ ) produced minor vacuoles in hepatocytes, while 
the double therapeutic dose $(70 \mathrm{mg} / \mathrm{kg}$ ) induced diffuse hydropic degenerations in the dam.
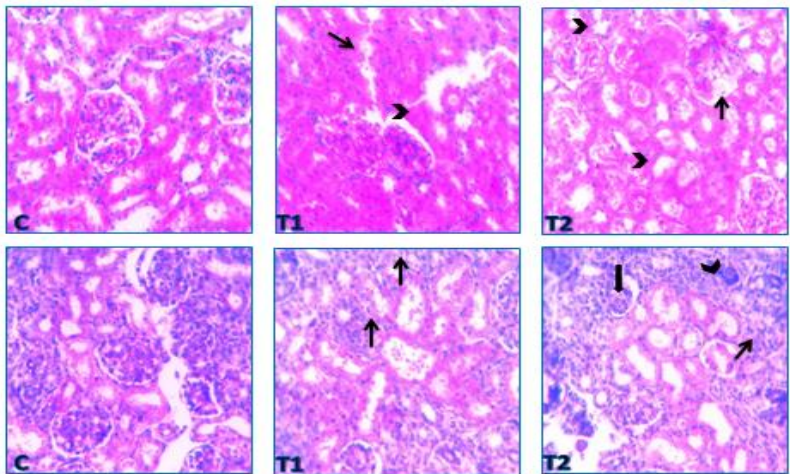

Figure 3. A: Kidney section of female rat where (C) kidney section of rat showing normal histological structure in control group, (T1) kidney section of rats given therapeutic dose of norfloxacin showing degenerated glomerulus (arrow) and tubules affected with cloudy swelling (arrowhead), (T2) kidney section of rats given double therapeutic dose of norfloxacin showing swollen endothelial cells lining glomerular tuft (arrows) and tubular dilation with hyaline cast (arrowheads). H\&E, X: 200. B: Kidney section of feti where (C) kidney section of feti obtained from control rats showing normal parenchyma and cellular details, (T1) kidney section of feti from rats given therapeutic dose of norfloxacin showing desquamated tubular epithelium (arrows) and tubular dilation, (T2) kidney section of feti from rats given double therapeutic dose of norfloxacin showing separated tubular epithelium (arrowhead) with tubular dilation (thick arrow) and mild fibroblast proliferation (thin arrow) in G3 (thin arrows) . H\&E, X: 200.

Therapeutic dose of norfloxacin $(35 \mathrm{mg} / \mathrm{kg}$ ) produced congested hepatic sinusoids and prominent Kupffer cells, while the double therapeutic dose $(70 \mathrm{mg} / \mathrm{kg})$ induced congestion in portal vein with surrounding mononuclear cells infiltration of markedly degenerated hepatocytes in feti.
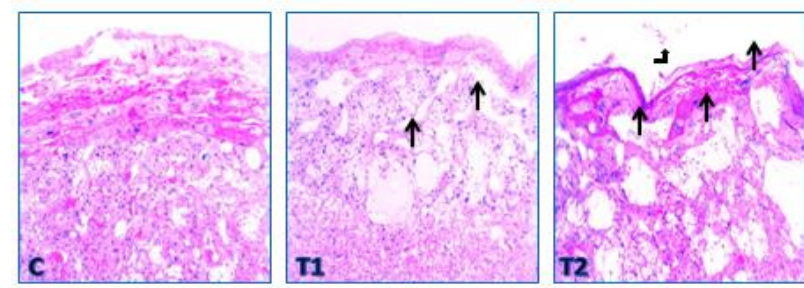

Figure 4. Placenta section of female rat where (C) section of rats showing normal histological structure in control group, (T1) section of rats given therapeutic dose of norfloxacin showing congestion in chorioallantoic blood vessels (arrows), (T2) section of rats given double therapeutic dose of norfloxacin showing severe congestion in chorioallantoic blood vessels (arrows) with degenerated trophoblasts (arrowheads) and atrophied giant cells (curved arrow). H\&E, X: 200.

\subsubsection{Kidney}

Therapeutic dose of norfloxacin $(35 \mathrm{mg} / \mathrm{kg}$ ) produced degenerated glomerulus and tubules affected with cloudy swelling, while the double therapeutic dose $(70 \mathrm{mg} / \mathrm{kg}$ ) induced swollen endothelial cells lining glomerular tuft and tubular dilation with hyaline cast in the dam.

Therapeutic dose of norfloxacin (35 $\mathrm{mg} / \mathrm{kg}$ ) produced desquamated tubular epithelium and tubular dilation, while the double therapeutic dose $(70 \mathrm{mg} / \mathrm{kg}$ ) induced separated tubular epithelium with tubular dilation and mild fibroblast proliferation in feti.

\subsubsection{Placenta}

Placental examination of dams received therapeutic dose of norfloxacin $(35 \mathrm{mg} / \mathrm{kg}$ ) revealed congestion in chorioallantoic blood vessels, while dams received the double therapeutic dose $(70 \mathrm{mg} / \mathrm{kg}$ ) revealed increased congestion in chorioallantoic blood vessels with degenerated trophoblasts and atrophied giant cells.

Table 4. Effect of norfloxacin at therapeutic ( $35 \mathrm{mg} / \mathrm{kg}$ bwt) and double therapeutic $\left(70 \mathrm{mg} / \mathrm{kg}\right.$ bwt) doses on $6^{\text {th }}$ to $15^{\text {th }}$ day of pregnancy on biochemical parameters of female rats (Mean $\pm S E$ ) $n=10$.

\begin{tabular}{llllllll} 
Group & $\begin{array}{l}\text { ALT } \\
(\mathrm{U} / \mathrm{ml})\end{array}$ & $\begin{array}{l}\text { AST } \\
(\mathrm{U} / \mathrm{ml})\end{array}$ & $\begin{array}{l}\text { Total } \\
\text { protein } \\
(\mathrm{g} / \mathrm{dl})\end{array}$ & $\begin{array}{l}\text { Albumin } \\
(\mathrm{g} / \mathrm{dl})\end{array}$ & $\begin{array}{l}\text { Globulin } \\
(\mathrm{g} / \mathrm{dl})\end{array}$ & $\begin{array}{l}\text { Urea } \\
(\mathrm{mg} / \mathrm{dl})\end{array}$ & $\begin{array}{l}\text { Creatinine } \\
(\mathrm{mg} / \mathrm{dl})\end{array}$ \\
\hline G1 & $26.45 \pm 0.9^{\mathrm{c}}$ & $75.83 \pm 0.14^{\mathrm{c}}$ & $6.68 \pm 0.1^{\mathrm{a}}$ & $4.43 \pm 0.05^{\mathrm{a}}$ & $2.25 \pm 0.10^{\mathrm{a}}$ & $27.90 \pm 0.40^{\mathrm{c}}$ & $0.72 \pm 0.03^{\mathrm{c}}$ \\
$\mathbf{G 2}$ & $30.91 \pm 0.41^{\mathrm{b}}$ & $80.31 \pm 0.93^{\mathrm{b}}$ & $5.75 \pm 0.12^{\mathrm{a}}$ & $3.32 \pm 0.13^{\mathrm{b}}$ & $2.43 \pm 0.2^{\mathrm{a}}$ & $29.58 \pm 0.77^{\mathrm{b}}$ & $0.85 \pm 0.01^{\mathrm{b}}$ \\
G3 & $33.05 \pm 058^{\mathrm{a}}$ & $84.66 \pm 0.25^{\mathrm{a}}$ & $4.94 \pm 0.10^{\mathrm{b}}$ & $2.44 \pm 0.7^{\mathrm{c}}$ & $2.50 \pm 0.11^{\mathrm{a}}$ & $31.26 \pm 0.28^{\mathrm{a}}$ & $0.90 \pm 0.03^{\mathrm{a}}$
\end{tabular}

Within the same column mean carry different superscript differ significantly at $(P<0.05)$

\section{DISCUSSION}

Oral administration of norfloxacin in both doses to pregnant rats during organogenesis period induced a marked decrease in number of viable fetuses, a significant decrease in fetal body weight, and crown-rump length, and a significant increase in the number of resorbed fetuses.

The decrease in number of viable feti may be attributed to the early embryonic death and the increase in fetal resorption ratio [3]. The reduction in fetal weight and length reported in the current study after the oral administration of norfloxacin might be attributed to disturbance in metabolism of certain minerals as magnesium and zinc in feti [16]. This finding are similar to that reported by previous experiments. Several fluoroquinolones as (enrofloxacin, ciprofloxacin, ofloxacin, and norfloxacin) used to treat infections in domestic animals (dogs, cats, pigs, cattle and poultry) have been reported to decrease the number of feti, and to increase the number of resorbed feti either early or late [17]. A decrease in litter size, and fetal weight, and an 
increase in fetal resorption ratio was detected, compared to the recorded value of the control group, after the administration of fluoroquinolones to rats [3]. The administration of norfloxacin to pregnant female rats induced a significant decrease in the number of viable feti, increase in the number of resorbed feti, and induced retardation in growth of viable feti $[5,18]$.

Results of the current experiment demonstrated that oral administration of norfloxacin in both doses to pregnant dams during organogenesis period induced numerous visceral abnormalities including diverticulum dilatation in the brain, hypoplasia of thymus gland, cardiac hyperplasia (thickening of the ventricular wall of the heart), a slight unilateral or bilateral widening of the renal pelvis and hypoplasia of one or both kidneys.

The brain defect (diverticulum dilatation) reported in feti after the administration of norfloxacin might have resulted from the lack of placental transfusion of amino acid and arginine which are important for the metabolism in feti. Hypoplasia of thymus gland reported in feti as a toxic effect of norfloxacin in rats were explained as due to cell death by converting topoisomerase II to cellular poison $[19,20]$. Cardiac hyperplasia appeared due to norfloxacin may be due to ability of fluoroquinolones to block cardiac potassium channel leading to prolonged QT intervals with cardiac arrhythmia and consequently cardiac hyperplasia [21]. The results of the current experiment are similar to those reported by previous work. Stahlmann [22] indicated that the administration of ofloxacin and ciprofloxacin to immature animal's induced cardiac hyperplasia. Similarly, Elkomy et al. [2], AL-Myahi et al. [3], Aboubakr et al. [5], and El Komy et al. [18] stated that the administration of both norfloxacin and difloxacin induced visceral malformation in pregnant rats.

Our results showed that administration of norfloxacin in both doses to pregnant rats during organogenesis period induced skeletal abnormalities in the form of impairment of skull ossification, short and irregular ribs, disappearance of strenebrae, caudal vertebrate and digital bones of fore and hind limb with absence of some metacarpal and metatarsal bone.

These skeletal abnormalities might be attributed to the accumulation of fluoride with repeated fluoroquinolone administration that causes bone and cartilage damage [23]. These findings are similar to those of Lemus et al. [24] who found that enrofloxacin and ciprofloxacin were associated with severe alterations in the development of embryo cartilage and bones in griffon vultures (Gyps fulvus) and red kites (Milvus milvus), two threatened avian scavengers. Also, Siddiqui et al. [25] reported that ciprofloxacin reduced the length of long bone extremities in rats. In addition, Hall et al. [26] revealed that fluoroquinolones were associated with a wide spectrum of musculoskeletal complications that involved not only tendon but also cartilage, bone, and muscle.
Oral administration of norfloxacin at both therapeutic and double therapeutic doses induced a significant increase in levels of serum transferases (ALT and AST), urea and creatinine, and a significant decrease in serum total portein, albumin and a non signficant change in serum globulin.

The presence of liver disease is often realized through the elevated serum activities of enzymes of hepatic origin which indicate either alteration in the integrity of the cell membrane or necrosis of hepatocytes. These liver enzymes leak from the injured hepatocytes to the serum, and its increased activity has a diagnostic importance [27]. ALT and AST are considered sensitive indictors of hepatocellular damage and, within limits, can provide a quantitative assessment of the degree of damage sustained by the liver [28].

In the current work, data revealed that the administration of both therapeutic and double therapeutic doses of norfloxacin caused significant alterations in liver functions reflected in significant elevations in serum transferases (ALT and AST) and significant reductions in serum total portein and albumin. These findings were further confirmed by the histopathological findings of liver. These results are similar to those reported by previoius work. Studies on ciprofloxacin revealed a decrease in total proteins content and a significant decrease in total protein of feti in rats [29]. Hypoalbuminemia were reported after repeated doses of oral norfloxacin in rats due to defect in albumin synthesis associated with impaired liver function [27]. In the same line, fluoroquinolones significantly increase AST, ALT in treated female rats due to mild hepatotoxicity $[30,31]$. Moreover, in human females, ciprofloxacin caused acute liver injury within a period of two days to two weeks following the initiation of antibiotic treatment resulting represented in hepatocellular necrosis and elevated liver enzymes [32]. Furthermore, increases in serum ALT and AST were reported in rats after administration of enrofloxacin [33]. The increased levels of serum ALT and AST detected in rats after administration of norfloxacin were referred to the oxidative stress where the production of oxidative radicals caused mitochondrial damage, RNA processing, transcription and inflammation that could serve as a mechanism for hepato-renal toxicity [34].

Serum creatinine is used mostly for observing and diagnosing kidney disease in human and animals. It is rapidly cleared from plasma and eliminated in urine, as a most efficient indirect marker of glomerular filtration rate (GFR) in mammals [27]. Its level is elevated in chronic and acute renal failure and in some other conditions not directly involve the kidney. Urea level in serum or plasma is also routinely used as a marker of GFR but is subjected to multiple extrarenal factors of variation. Both urea and creatinine are almost totally eliminated by glomerular filtration, therefore their concentrations in plasma are elevated in renal failure [27].

In the present study the administration of norfloxacin at therapeutic and double therapeutic doses to female rats 
provoked a marked increase in serum urea and creatinine levels. These findings agree with those of previous experiments. Nephrotoxicity with increased serum creatinine, serum urea, and creatinine clearance was detected in rats after administration of ciprofloxacin, fluoroquinolones and norfloxacin [30, 34, 35, 36].

Oral administration of norfloxacin in both doses to pregnant rats during organogenesis period induced various pathological alterations. The reported histopathological picture of liver and Kidney of treated dams are supported by findings of previous experiments. Mild interstitial nephritis were reported with the use of various fluoroquinolones (norfloxacin, ciprofloxacin and ofloxacin) [37]. The administration of ciprofloxacin in humans was associated with histopathological changes in liver and kidney [38, 39, $40,41]$. Oral administration of $2 \times 250 \mathrm{mg}$ ciprofloxacin per day to a 22-year-old male caused acute liver failure 14 days later. Liver biopsy revealed extensive hepatocellular necrosis involving zones 3 and 2 of hepatic acini and a mixed inflammatory infiltration containing abundant eosinophils [42]. Ciprofloxacin induced pathological changes in liver of pregnant rats in the form of dilatation of central and portal vein, and sinusoidal spaces, appearance of macrophages and Kupffer cells in sinusoidal spaces and congestion in blood vessels, and that the liver sections of feti obtained from pregnant rats revealed similar histopathological alterations as that of mothers [29]. Furthermore, norfloxacin evoked histopathological alterations in liver, kidney, heart, spleen and intestine of treated rats [30]. Also, oral administration of norfloxacin induced granulomatous interstitial nephritis $[43,44]$. Also, histopathological examination of internal organs of pregnant rats following oral administration of both doses of norfloxacin from $6^{\text {th }}$ day of pregnancy revealed various pathological changes in liver, kidney, brain and placenta $[3,5,18]$.

\section{CONCLUSION}

The administration of norfloxacin during early stage of pregnancy of rats in high doses induced fetal abnormalities and defects, therefore it is advisable to avoid its use during pregnancy.

\section{Acknowledgment}

The authors wish to acknowledge the staff members of Pharmacology Department for their help, facilitates and encouragement during the course of this study.

\section{Conflict of interest statement}

The authors declare that there is no conflict of interest in the current research work.

\section{Animal ethics committee permission}

The current research work was permitted by Research Ethics Committee, Faculty of Veterinary Medicine, Mansoura University.

\section{Authors' contributions}

Eman Soliman and Rasha Abdel-Gelil performed the experiment, statistical analysis, and wrote the manuscript, Galal Youssef performed the anatomical dissection of viscera, Nani Nasreldin performed the biochemical assay and participated in writing the manuscript, Magdy Amer revised the manuscript and supervised the whole work.

\section{REFFERENCES}

[1] Jamkhande PG, Chintawar KD, Chandak PG. Teratogenicity: a mechanism based short review on common teratogenic agents. Asian Pacific Journal of Tropical Disease. 2014;4:421-32. https://doi.org/10.1016/S2222-1808(14)60600-9

[2] Elkomy A, Aboubakr M, Medhat N. Some teratological effects of difloxacin in rats. Benha Veterinary Medical Journal. 2016;30:266-71. https://doi.org/10.21608/bvmj.2016.31373

[3] AL-Myahi AJ, AL-Musawy AAH, Al-Snafi AE. Embryotoxicity of fluoroquinolones in rats. Thi-Qar Medical Journal. 2011;5:77-86.

[4] Mehlhorn AJ, Brown DA. Safety Concerns with Fluoroquinolones. Annals of Pharmacotherapy. 2007;41:1859-66. https://doi.org/10.1345/aph.1K347

[5] Aboubakr M, Elbadawy M, Soliman A, El-Hewaity M. Embryotoxic and Teratogenic Effects of Norfloxacin in Pregnant Female Albino Rats. Advances in Pharmacological Sciences. 2014;2014:1-6. https://doi.org/10.1155/2014/924706

[6] Paget GE, Barnes JM. Toxicity Tests. Evaluation of Drug Activities: Elsevier; 1964. p. 135-66. https://doi.org/10.1016/B978-1-4832-28457.50012-8

[7] Scorza Barcellona P, Fanelli O, Campana A. Teratological study of etoperidone in the rat and rabbit. Toxicology. 1977;8:87-94. https://doi.org/10.1016/0300-483x(77)90026-9

[8] Cahen RL. Experimental and Clinical Chemoteratogenesis. Advances in Pharmacology: $\quad$ Elsevier; $1966 . \quad$ p. 263-349. https://doi.org/10.1016/S1054-3589(08)60101-5

[9] Snell K. Development Toxicology: Croom Helm; 1982.

[10] Hayes AW. Principles and Methods of Toxicology. $2^{\text {nd }}$ ed1988. p. 32059.

[11] Hayes AW. Chromosomal rearrangements. Journal of the National Cancer Institute. 1986;77:1211-5.

[12] Staples R. Refinements in rapid clearing technic in the $\mathrm{KOH}$-alizarin red S method for fetal bone. Stain Technology. 1964;39:61-3.

[13] Bancroft J, Stevens A, Turner D. Theory and practice of histological techniques $4^{\text {th }}$ Ed Churchill Living Stone, New York Edinburgh. Madrid, Sanfrancisco. 1996.

[14] Stoffregen DA, Wooster GA, Bustos PS, Bowser PR, Babish JG. Multiple route and dose pharmacokinetics of enrofloxacin in juvenile Atlantic salmon. Journal of Veterinary Pharmacology and Therapeutics. 1997;20:111-23. https://doi.org/10.1046/j.1365-2885.1997.81531.x

[16] Clemens G, Hartnagel R. A teratology (Segment II) study in the rat with BAY Vp 2674. Unpublished Report. 1985.

[17] Vancutsem P, Babish J, Schwark W. The fluoroquinolone antimicrobials: structure, antimicrobial activity, pharmacokinetics, clinical use in domestic animals and toxicity. The Cornell Veterinarian. 1990;80:17386.

[18] El Komy A, El-Meleh A, Elzoghby R, Salem A. Effect of norfloxacin on fetal developments in pregnant female albino rats. World Journal of Pharmacy and Pharmaceutical Sciences. 2017;6:46-59.

[19] Zhang L-R, Wang Y-M, Chen B-Y, Cheng N-N. Neurotoxicity and toxicokinetics of norfloxacin in conscious rats. Acta Pharmacologica Sinica. 2003;24:605-9.

[20] Elsea SH, McGuirk PR, Gootz TD, Moynihan M, Osheroff N. Drug features that contribute to the activity of quinolones against mammalian topoisomerase II and cultured cells: correlation between enhancement of enzyme-mediated DNA cleavage in vitro and cytotoxic potential. Antimicrobial Agents and Chemotherapy. 1993;37:2179-86. https://doi.org/10.1128/AAC.37.10.2179

[21] Kang J, Wang L, Chen X-L, Triggle DJ, Rampe D. Interactions of a Series of Fluoroquinolone Antibacterial Drugs with the Human Cardiac K+Channel HERG. Molecular Pharmacology. 2001;59:122-6. https://doi.org/10.1124/mol.59.1.122 
[22] Stahlmann R. Safety profile of the quinolones. Journal of Antimicrobial Chemotherapy.

$1990 ; 26: 31-44$ https://doi.org/10.1093/jac/26.suppl_D.31

[23] Arora NK. Are fluoroquinolones safe in children? The Indian Journal of Pediatrics. 1994;61:601-3. https://doi.org/10.1007/BF02751963

[24] Lemus JÁ, Blanco G, Arroyo B, Martínez F, Grande J. Fatal embryo chondral damage associated with fluoroquinolones in eggs of threatened avian scavengers. Environmental Pollution. 2009;157:2421-7. https://doi.org/10.1016/j.envpol.2009.03.013

[25] Siddiqui M, Naqvi S. Evaluation of the teratogenic potentials of ciprofloxacin in albino rat. Journal of Morphological Sciences. 2017;27:14-8.

[26] Hall MM, Finnoff JT, Smith J. Musculoskeletal Complications of Fluoroquinolones: Guidelines and Precautions for Usage in the Athletic Population. PM\&R. 2011;3:132-42. https://doi.org/10.1016/j.pmrj.2010.10.003

[27] Kaneko JJ, Harvey JW, Bruss ML. Preface. Clinical Biochemistry of Domestic Animals. $6^{\text {th }}$ ed: Elsevier; 2008. p. ix. https://doi.org/10.1016/B978-0-12-370491-7.00031-3

[28] Peng D, Chen S, Ruan L, Li L, Yu Z, Sun M. Safety assessment of transgenic Bacillus thuringiensis with VIP insecticidal protein gene by feeding studies. Food and Chemical Toxicology. 2007;45:1179-85. https://doi.org/10.1016/j.fct.2006.12.026

[29] Ismail NH. Assessment of histopathological and histochemical changes in liver of pregnant female rats and their fetuses following Ciprofloxacin administration. Egyptian Society of Clinical Toxcology Journal. 2006;35:7-17.

[30] Rashmi R, Jayakumar K, Narayana Swamy H, Bayer M. Organ directed toxicity of norfloxacin in a repeated dose 28 day oral toxicity study in female rats. International Journal of Pharma and Bio Sciences. 2012;3:81-95.

[31] Ore A, Olayinka ET. Influence of Moxifloxacin on Hepatic Redox Status and Plasma Biomarkers of Hepatotoxicity and Nephrotoxicity in Rat. Biochemistry Research International. 2015;2015:1-8. https://doi.org/10.1155/2015/192724

[32] Qutrio Baloch Z, Raza MA, Abbas SA, Bukhari S. Ciprofloxacin-induced Hepatotoxicity in a Healthy Young Adult. Cureus. 2017. https://doi.org/10.7759/cureus.1016

[33] Barski D, Spodniewska A. Effect of chlorpyrifos and enrofloxacin on selected enzymes in rats. Polish Journal of Veterinary Sciences. 2018;21:39-46.

[34] Khalifa HA, Shalaby SI, Abdelaziz AS. Alhagi maurorum aqueous extract protects against norfloxacin-induced hepato-nephrotoxicity in rats. Chinese Herbal Medicines. 2019 https://doi.org/10.1016/j.chmed.2019.09.007

[35] Başaran A, Erol K, Başaran N, Güneş HVV, Açikalin E, Timuralp G, et al. Effects of Ciprofloxacin on Chromosomes, and Hepatic and Renal Functions in Rats. Chemotherapy. 1993;39:182-8. https://doi.org/10.1159/000239124

[36] Lomaestro BM. Fluoroquinolone-Induced Renal Failure. Drug Safety. 2000;22:479-85. https://doi.org/10.2165/00002018-20002206000006

[37] Patterson DR. Quinolone toxicity: Methods of assessment. The American Journal of Medicine. 1991;91:S35-S7. https://doi.org/10.1016/0002-9343(91)90308-K

[38] Contreras MÁ, Luna R, Mulero J, Andreu JL. Severe CiprofloxacinInduced Acute Hepatitis. European Journal of Clinical Microbiology and Infections Diseases. 2001;20:0434-5. https://doi.org/10.1007/s100960100513

[39] Bataille L, Rahier J, Geubel A. Delayed and prolonged cholestatic hepatitis with ductopenia after long-term ciprofloxacin therapy for Crohn's disease. Journal of Hepatology. 2002;37:696-9. https://doi.org/10.1016/S0168-8278(02)00268-4

[40] Goetz M, Galle PR, Schwarting A. Non-Fatal Acute Liver Injury Possibly Related to High-Dose Ciprofloxacin. European Journal of Clinical Microbiology and Infectious Diseases. 2003;22:294-6. https://doi.org/10.1007/s10096-003-0914-6

[41] Xie HJ, Griskevicius L, Broberg U, Lundgren S, Carlens S, Meurling L, et al. Alteration of pharmacokinetics of cyclophosphamide and suppression of the cytochrome P450 genes by ciprofloxacin. Bone Marrow Transplantation. 2003;31:197-203.
[42] Zimpfer A, Propst A, Mikuz G, Vogel W, Terracciano L, Stadlmann S. Ciprofloxacin-induced acute liver injury: case report and review of literature. Virchows Archiv. 2004;444:87-9. https://doi.org/10.1007/s00428-003-0917-9

[43] Ramalakshmi S, Bastacky S, Johnson JP. Levofloxacin-induced granulomatous interstitial nephritis. American Journal of Kidney Diseases. https://doi.org/10.1053/ajkd.2003.50064

[44] Al-Shawi NN. Possible Histological Changes Induced by Therapeutic Doses of Ciprofloxacin in Liver and Kidney of Juvenile Rats. Pharmacologia. 2012:3:477-80. https://doi.org/10.1038/sj.bmt.1703815 